\title{
STUDI ANALISIS GANGGUAN PERANGKAT HUBUNG BAGI TEGANGAN RENDAH DAN UPAYA MENGATASINYA DI PLN AREA TANJUNG PRIOK
}

\author{
Tri Joko Pramono'), Ibnu Hajar ${ }^{2)}$, Sri Wahyuni ${ }^{3)}$ \\ Teknik Elektro, Sekolah Tinggi Teknik - PLN \\ email : 'trijoko_pramono@yahoo.co.id \\ 2ibnu.hjr@gmail.com \\ ${ }^{3}$ sriwahyuni.rahim@yahoo.co.id
}

\begin{abstract}
Medium voltage feeders are a means for the distribution of electricity from substations to consumers. But in reality these feeders often experience interference, among other is interference onthe low voltage network, especiallyCircuit For Low Voltage Device. Circuit For Low Voltage Device (PHB-TR) is device used as a liaison, security, and dividers electrical power from an electric power source to the customer. Over time, the PHB-TR also decreased quality of service so that should be their efforts to overcome the problems in order to maintain or restore the initial achievement level and can operate with high reliability so that the continuity of the electrical service will be achieved. The disturbances that can occur in this PHB-TR as damage to the NH fuse, corona contained in ground plate, over current and damage to the measuring instrument.Additionally by overcoming the interference can secure the assets of PLN from the interferences and reduce the cost of replacing broken tools.
\end{abstract}

Keywords: Device circuit For Low Voltage (PHB-TR)

Abstrak : Penyulang tegangan menengah adalah sarana untuk pendistribusian listrik dari gardu induk ke konsumen. Tetapi dalam kenyataannya penyulang tersebut sering mengalami gangguan, diantaranya gangguan pada jaringan tegangan rendah khususnya Perangkat Hubung Bagi Tegangan Rendah. Perangkat Hubung Bagi Tegangan Rendah (PHB-TR) murapakan perangkat yang digunakan sebagai penghubung, pengaman, dan pembagi tenaga listrik dari sumber tenaga listrik ke pelanggan. Seiring dengan berjalannya waktu, maka PHB-TR pun mengalami penurunan kualitas pelayanan sehingga perlu dilakukan adanya upaya untuk mengatasi gangguan agar dapat mempertahankan atau mengembalikan pada tingkat prestasi awal dan dapat beroperasi dengan keandalan yang tinggi sehingga kontinuitas pelayanan listrik akan tercapai. Selain itu dengan cara mengatasi gangguan dapat mengamankan aset PLN dari gangguan gangguan dan menekan biaya penggantian alat rusak.

Kata Kunci : Perangkat Hubung Bagi Tegangan Rendah (PHB-TR)

\section{PENDAHULUAN}

Seiring jaman yang semakin maju dan meningkatnya kebutuhan tenaga listrik tiap tahun, maka dibutuhkan pasokan listrik yang mencukupi bagi seluruh konsumen masyarakat, industri, maupun gedung perkantoran. Energi listrik dapat disalurkan ke konsumen melalui suatu sistem jaringan. Sistem jaringan terdiri dari unit pembangkit dan unit penyalur berupa perlengkapan tenaga listrik yang terpasang pada gardu-gardu, baik itu gardu induk maupun gardu distribusi yang dioperasikan secara otomatis dan manual. Kegiatannya mencakup pengaturan, pembagian, pemindahan, dan penyaluran tenaga listrik dari pusat pembangkit kepada konsumen dengan efektif serta menjamin kelangsungan penyaluran dan pelayanannya.

Gardu distribusi merupakan sarana penyaluran tenaga listrik dari PLN ke pelanggan. Dengan tegangan primer 20 $k V$ lalu diubah oleh trafo menjadi tegangan sekunder $380 \mathrm{~V}$ (antar fasa) 
atau $220 \mathrm{~V}$ (fasa - netral). Pelanggan yang menggunakan ini adalah pelanggan TR, baik industri maupun rumah tangga.

Salah satu aset PLN yang menjadi bagian dari sorotan penelitian ini adalah mengenai upaya menanggulangi gangguan pada PHB TR. Supaya kontinuitas penyaluran listrik ke konsumen tidak terganggu maka diperlukan PHB TR gardu distribusi dengan mutu yang baik, sehingga tidak di dapati PHB TR atau komponennya yang mengalami kerusakan.

Gangguan pada PHB TR ini dapat terjadi karena beban yang berlebih, terjadi korona pada ground plat, rel ataupun baut, gangguan pada $\mathrm{NH}$ fuse. Tidak dipungkiri

bahwa kondisi yang selama ini terjadi di lapangan, disebabkan oleh hal-hal tersebut. Adapun tujuan penelitian ini adalah : mengetahui kinerja dari peralatan Hubung Bagi Tegangan Rendah (PHB TR) dalam penyuplaian tenaga listrik ke konsumen; mengetahui gangguangangguan yang dapat terjadi pada Peralatan Hubung Bagi Tegangan Rendah (PHB TR); mengetahui upaya mengatasi gangguan jaringan listrik tegangan rendah khususnya pada Peralatan Hubung Bagi Tegangan Rendah (PHB TR).

\section{LANDASAN TEORI}

\subsection{Proses Pendistribusian Energi Listrik}

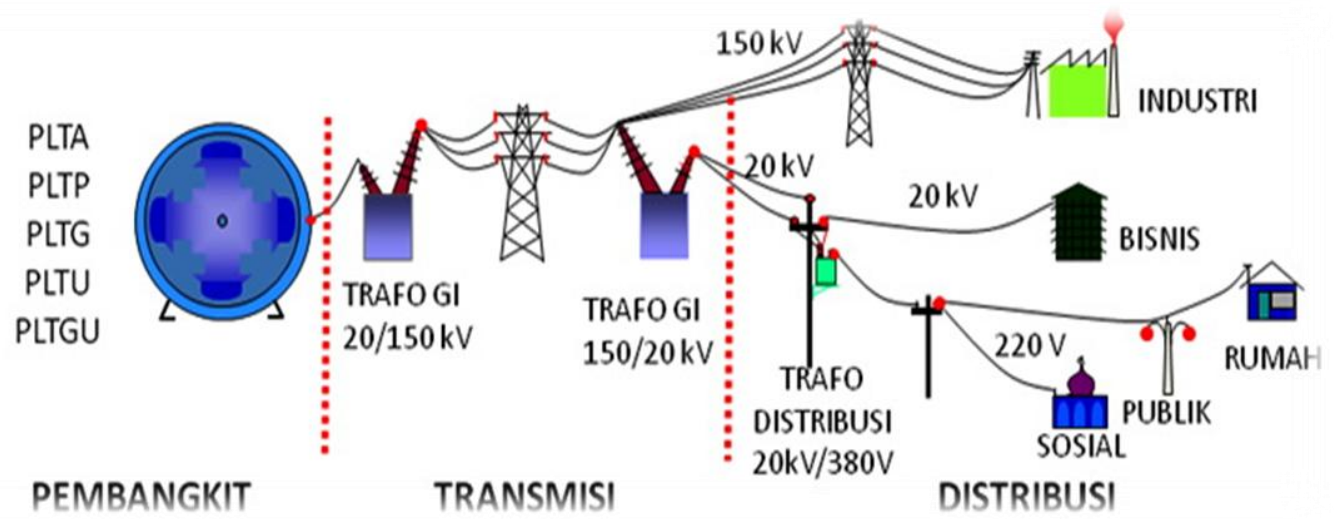

Gambar 1. Proses Pendistribusian Energi Listrik

Setelah tenaga listrik dibangkitkan oleh suatu pusat pembangkit listrik, selanjutnya tenaga listrik disalurkan (ditransmisikan) melalui jaringan transmisi. Dari jaringan transmisi selanjutnya didistribusikan kepada para konsumen tenaga listrik melalui jaringan distribusi tenaga listrik. Pada PTL (Pembangkit Tenaga Listrik) biasanya membangkitkan energi listrik pada tegangan menengah, yaitu pada umumnya antara $6-20 \mathrm{kV}$, pada sistem tenaga listrik besar atau jika PTL terletak jauh dari pemakai, maka tegangannya perlu dinaikan melalui saluran transmisi dari dari tegangan menengah (TM) menjadi tegangan tinggi (TT) bahkan tegangan ekstra tinggi (TET).

Pada pembangkit tegangan yang dikeluarkan oleh generator yaitu $16 \mathrm{KV}$ kemudian dinaikan tegangannya melalui Trafo Step-up di GITET hingga tegangannya menjadi $500 \mathrm{KV}$, kemudian dialurkan melalui SUTET untuk menuju ke konsumen pemakai tegangan tinggi, sebelum ke konsumen pemakai tegangan tinggi tegangan terlebih dahulu diturunkan dari TET menjadi TT yaitu sekitar $150 \mathrm{KV}$, tegangan tersebut diturunkan melalui Trafo step-down yang berada di Gardu Induk (GI).

Setelah itu listrik dialirkan melalui SUTT menuju ke konsumen pemakai Tegangan Menengah, sebelum ke konsumen pemakai (TM), tegangan diturunkan kembali oleh Gardu Induk melalui Trafo step-down, dari (TT) menjadi (TM) yaitu sekitar $20 \mathrm{KV}$.

Mendekati pusat pemakaian tenaga listrik yang umum, enrgi listrik yang dialirkan melalui JTM tegangan diturunkan, dari TM menjadi TR oleh Trafo stepdown di gardu distribusi, tegangannya yaitu 220 dan 380 volt, yang kemudian didistribusikan ke pemakai oleh gardu distribusi melalui JTR. 


\subsection{Gardu Distribusi}

Gardu distribusi tenaga listrik adalah suatu bangunan gardu listrik yang dipasok dengan tegangan menengah $20 \mathrm{kV}$ dari saluran kabel tegangan menengah atau saluran udara tegangan menengah. Berisi atau terdiri dari instalasi Perlengkapan Hubung Bagi Tegangan Menengah (PHBTM), Transformator Distribusi (TD) dan Perlengkapan Hubung Bagi Tegangan Rendah (PHB-TR) untuk memasok kebutuhan tenaga listrik bagi para pelanggan baik dengan Tegangan Menengah (TM $20 \mathrm{kV}$ ) maupun Tegangan Rendah (TR 220/380 V). Konstruksi gardu distribusi dirancang berdasarkan optimalisasi biaya terhadap maksud dan tujuan penggunaannya yang kadang kala harus disesuaikan dengan Peraturan Pemda setempat.

Pembangunan gardu distribusi terdiri dari: gardu pasangan luar dimana semua instalasi listriknya kedap air (gardu portal atau gardu cantol) dan gardu pasangan dalam dimana instalasinya tidak kedap air (gardu beton atau gardu kios). Jenis konstruksinya: gardu beton (bangunan sipil: batu, beton) gardu tiang (gardu cantol dan gardu portal).

Jenis penggunaan: gardu pelanggan umum (daya $<200$ kVA) dengan kapasitas trafo distribusi/tenaga yang terpasang di gardu distribusi 50 kVA s/d 1000 kVA dan gardu pelanggan khusus (daya 200 kVA) dengan langganan TM/TM/TM atau TM/ TM/TR atau TM/TM/TR yang dilengkapi trafo distribusi. Khusus pengertian Gardu Hubung adalah gardu yang ditujukan untuk memudahkan manuver pembebanan dari satu penyulang ke penyulang lain yang dapat dilengkapi/tidak dilengkapi RTU (Remote Terminal Unit). Untuk fasilitas ini lazimnya dilengkapi fasilitas DC Supply dari Trafo Distribusi pemakaian sendiri atau Trafo distribusi untuk umum yang diletakkan dalam satu kesatuan.

\subsection{Perangkat Hubung Bagi Tegangan Rendah (PHB-TR)}

PHB-TR adalah suatu kombinasi dari satu atau lebih Perangkat Hubung Bagi Tegangan Rendah dengan peralatan kontrol, peralatan ukur, pengaman dan kendali yang saling berhubungan. Keseluruhannya dirakit lengkap dengan sistem pengawatan dan mekanis pada bagian-bagian penyangganya.

Secara umum PHB TR sesuai SPLN 118-3-1-1996, untuk pasangan dalam adalah jenis terbuka. PHB TR pasangan dalam untuk gardu distribusi beton. PHB jenis terbuka adalah suatu rakitan PHB yang terdiri dari susunan penyangga peralatan proteksi dan peralatan Hubung Bagi dengan seluruh bagian-bagian yang bertegangan, terpasang tanpa isolasi. Jumlah jurusan per transformator atau gardu distribusi sebanyak-banyaknya 8 jurusan, disesuaikan dengan besar daya transformator dan Kemampuan Hantar Arus (KHA) Penghantar JTR yang digunakan. Pada PHB-TR harus dicantumkan diagram satu garis, arus pengenal gawai proteksi dan kendali serta nama jurusan JTR.

\section{METODE PENELITIAN}

\subsection{Karakteristik Listrik PHB-TR}

1. Tegangan pengenal $230 / 400 \mathrm{~V}$

2. Frekuersi pengenal $50 \mathrm{~Hz}$

3. Tingkat isolasi dasar (puncak) $6 \mathrm{kV}$

4. Arus ketahananwaktu singkat selama 1 detik :
a. PHB 250/500/630 A $15 \mathrm{kA}$
b. PHB $800 \mathrm{~A} \quad 20 \mathrm{kA}$
c. PHB $1200 \mathrm{~A} 25 \mathrm{kA}$
d. PHB 2000A $35 \mathrm{kA}$

5. Nilai pengenal arus busbar $250 / 400 /$ 500/630/800/1200/2000A

6. pengaman lebur HRC25 kA/400 V

7. Tegangan ketahanan frekuensi daya selama 1 menit $2,5 \mathrm{kV}$ 
Tabel 1. Ukuran Busbar Tembaga

\begin{tabular}{|c|c|c|c|c|c|c|}
\hline \multirow[b]{2}{*}{$\begin{array}{l}\text { Jenis } \\
\text { PHB TR }\end{array}$} & \multicolumn{2}{|c|}{ Busbar Kolektor } & \multicolumn{2}{|c|}{ Busbar Penghubung } & \multicolumn{2}{|c|}{ Busbar Keluaran } \\
\hline & Fasa & Netral & Fasa & Netral & Fasa & Netral \\
\hline $250 \mathrm{~A}$ & $30 \times 5 \mathrm{~mm}$ & $30 \times 5 \mathrm{~mm}$ & $30 \times 5 \mathrm{~mm}$ & $30 \times 5 \mathrm{~mm}$ & $20 \times 5 \mathrm{~mm}$ & $20 \times 5 \mathrm{~mm}$ \\
\hline $400 \mathrm{~A}$ & $40 \times 5 \mathrm{~mm}$ & $40 \times 5 \mathrm{~mm}$ & $40 \times 5 \mathrm{~mm}$ & $40 \times 5 \mathrm{~mm}$ & $30 \times 5 \mathrm{~mm}$ & $30 \times 5 \mathrm{~mm}$ \\
\hline $500 / 630 \mathrm{~A}$ & $50 \times 5 \mathrm{~mm}$ & $50 \times 5 \mathrm{~mm}$ & $50 \times 5 \mathrm{~mm}$ & $50 \times 5 \mathrm{~mm}$ & $30 \times 5 \mathrm{~mm}$ & $30 \times 5 \mathrm{~mm}$ \\
\hline $800 \mathrm{~A}$ & $60 \times 5 \mathrm{~mm}$ & $60 \times 5 \mathrm{~mm}$ & $60 \times 5 \mathrm{~mm}$ & $60 \times 5 \mathrm{~mm}$ & $40 \times 5 \mathrm{~mm}$ & $40 \times 5 \mathrm{~mm}$ \\
\hline $1200 \mathrm{~A}$ & $80 \times 10 \mathrm{~mm}$ & $80 \times 10 \mathrm{~mm}$ & $80 \times 10 \mathrm{~mm}$ & $80 \times 5 \mathrm{~mm}$ & $40 \times 10 \mathrm{~mm}$ & $40 \times 5 \mathrm{~mm}$ \\
\hline $2000 \mathrm{~A}$ & $2(80 \times 10) \mathrm{mm}$ & $80 \times 10 \mathrm{~mm}$ & $2(80 \times 10) \mathrm{mm}$ & $80 \times 10 \mathrm{~mm}$ & $40 \times 10 \mathrm{~mm}$ & $40 \times 5 \mathrm{~mm}$ \\
\hline
\end{tabular}

Busbar tembaga harus dicat dengan warna sebagai berikut :
a) Busbar Fase : Merah, Kuning, Hitam
b) Busbar Netral: Biru
c) Busbar Pembumian : Hijau dengan strip kuning
d) Setiap sambungan busbar harus diberi lapisan timah atau perak. Catatan: Warna disesuaikan SPLN 104 : 1993 mengenai warna standar

\subsection{Komponen-Komponen PHB-TR}

Pada dasarnya jenis komponen yang dipasang disesuaikan dengan keperluan.

Standar komponen menurut SPLN 118-3-1:1996 adalah sebagai berikut:

a. Untuk PHB TR Pasangan Dalam: 1) Satu unit masukan $400 A-2000$

2) Sistem busbar $400 \mathrm{~A}-2000 \mathrm{~A}$

3) Empat unit keluaran utama (dapat dimodifikasi menjadi delapan saluran keluaran)

4) Satu keluaran untuk penerangan gardu distribusi

5) Satu keluaran untuk penerangan umum

6) Satu keluaran untuk lampu indikator hubung singkat

7) Tiga amperemeter kebutuhan maksimum dan trafo arus 600800-1200-2000 A/5A

Catatan: Harus sesuai untuk pemasangan di atas lantai dan dinding beton/tembok b. Untuk PHB TR Pasangan Luar:

1) Satu unit masukan $250 \mathrm{~A}$ atau $500 \mathrm{~A}$

2) Sistem busbar $250 \mathrm{~A}$ atau $500 \mathrm{~A}$

3) Empat unit keluaran utama

4) Satu keluaran untuk penerangan panel

5) Satu keluaran untuk penerangan umum

6) Tiga amperemeter kebutuhan maksimum dan trafo arus $250 / 5 \mathrm{~A}$ Catatan: Harus dengan kabinet yang kedap air dan rayap maupun bintangbintang kecil dapat masuk ke dalamnya

\subsection{Menghitung Arus NH Fuse}

Berikut adalah rumus menghitung arus NH Fuse

$$
\begin{aligned}
& \ln =\frac{\text { Kapasistasitrafo } \quad(\text { Volt / Ampere })}{\sqrt{3} x \text { Teganganfasa }- \text { fasa }(\text { Volt })} \\
& \text { Arustiapjurusan }=\frac{\ln (\text { Ampere })}{\sum \text { jurusandiPHB }-T R} \\
& \text { KHANHFusedipilih }=\text { Arustiapjurusan } 0,9
\end{aligned}
$$

Catatan :

Faktor kali 0,9 adalah factor keamanan untuk beban trafo

KHA NH Fuse untuk daya trafo dan jurusan dapat dilihat tabel di bawah ini: $($ Beban $=90 \%)$ 
Tabel 2. KHA NH Fuse

\begin{tabular}{|c|c|c|c|c|c|c|c|c|}
\hline \multirow{3}{*}{ No } & \multirow{3}{*}{$\begin{array}{c}\text { DAYA } \\
\text { TRAFO } \\
\text { (KVA) }\end{array}$} & \multicolumn{7}{|c|}{ NH FUSE (AMP), $V_{\text {ph-ph }}=400$ volt } \\
\hline & & \multicolumn{7}{|c|}{ JUMLAH JURUSAN } \\
\hline & & 1 & 2 & 3 & 4 & 5 & 6 & 7 \\
\hline 1 & 100 & 120 & 60 & & & & & \\
\hline 2 & 200 & 250 & 120 & 85 & 65 & & & \\
\hline 3 & 315 & 400 & 200 & 135 & 100 & & & \\
\hline 4 & 400 & 510 & 250 & 170 & 125 & 100 & 85 & \\
\hline 5 & 630 & 800 & 400 & 275 & 200 & 160 & 135 & 110 \\
\hline
\end{tabular}

\section{HASIL DAN PEMBAHASAN}

\subsection{Material Penyebab Gangguan Yang Terjadi Pada PHB TR}

Tabel 3. Jumlah Material Penyebab Gangguan PHB TR Februari-Mei 2016

\begin{tabular}{|c|l|c|}
\hline No. & \multicolumn{1}{|c|}{ Material } & $\begin{array}{c}\text { Jumlah } \\
\text { Kerusakan }\end{array}$ \\
\hline 1. & NH Fuse Putus & 258 \\
\hline 2. & Fuse Base Rusak & 134 \\
\hline 3. & $\begin{array}{l}\text { Pemasangan } \\
\text { Bendingan }\end{array}$ & 53 \\
\hline 4. & Sepatu Kabel Rusak & 6 \\
\hline \multicolumn{2}{|c|}{ Jumlah } & 451 \\
\hline
\end{tabular}

\subsubsection{Analisa NH fuse putus}

Berdasarkan tabel 4.1, gangguan putusnya NH Fuse merupakan salah satu gangguan yang sering terjadi pada jaringan tegangan rendah yaitu sebanyak 258 kali selama bulan Februari-Mei 2016.

Hasil inspeksi pada gardu SD 134 dengan gangguan $\mathrm{NH}$ Fuse putus sebanyak 7 kali selama bulan FebruariMei 2016 (Lampiran B), dengan kapasitas fuse yang terpasang sebesar 250A, hal ini terjadi dikarenakan gangguan pada sistem dan akibat beban lebih (overload), penyebab dari beban lebih ini adalah adanya pemasangan listrik baru, bisa juga karena pemakaian listrik yang berlebihan pada konsumen sehingga semua peralatan dirumah yang memakai listrik digunakan seluruhnya, maka secara otomatis pemakaian listrik yang semula biasa menjadi berlebihan.

Kelebihan beban juga dapat disebabkan karena adanya penerangan jalan umum dengan menggunakan sistem cantol langsung pada saluran listrik tanpa melalui kWH meter, sehingga kapasitas
NH Fuse yang terpasang pada gardu tidak mampu lagi menahan beban dan menyebabkan NH Fuse putus.

Indikator $\mathrm{NH}$ Fuse putus secara umum dapat dilihat dari munculnya tonjolan merah pada fisik $\mathrm{NH}$ fuse. $\mathrm{NH}$ fuse yang telah rusak harus diganti, dalam membuka / memasang $\mathrm{NH}$ fuse tidak boleh mempergunakan tang atau peralatan lain karena akan merusak $\mathrm{NH}$ fuse itu sendiri, maka digunakan Puller untuk memasang dan melepas pengaman lebur (NH fuse).

\subsubsection{Analisa Fuse Base Rusak (Ground Plat Rusak)}

Fuse base adalah kedudukan dasar $\mathrm{NH}$ fuse dimana komponen ini berbentuk jepitan dengan dua permukaan bidang kontak. Fuse base ini berfungsi untuk menjepit fuse dan sebagai titik kontak penghubung antara busbar dan saluran pembagi serta merupakan alat kontak yang terbuat dari tembaga. Penyebab kerusakan dari fuse base ini adalah loss kontak dari fuse base tersebut. Apabila daya jepit dari fuse base itu berkurang maka NH Fuse yang terpasang menjadi kendor dan hal itu dapat mengakibatkan panas karena adanya percikan bunga api yang lama kelamaan dapat menimbulka putusnya fuse. 

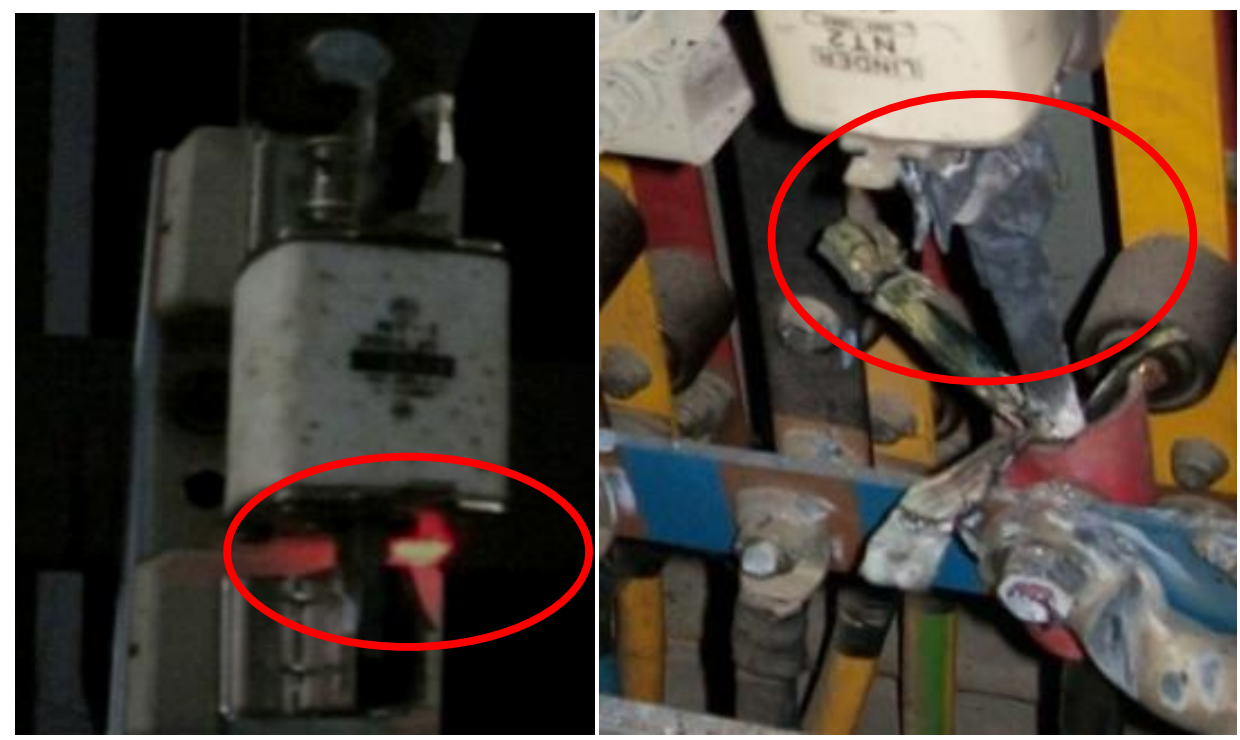

Gambar 2. Fuse Base Rusak

Hasil inspeksi pada gardu PK137A dengan gangguan $\mathrm{NH}$ Fuse putus sebanyak 6 kali selama bulan Februari 2016 (Lampiran C), feeder B dengan kondisi fuse base rusak beban 225A, fuse terpasang $300 \mathrm{~A}$, suhu pada pisau fuse base $135^{\circ} \mathrm{C}$ dengan suhu ruangan $\mathrm{PHB}$ TR $40^{\circ} \mathrm{C}$, melebihi standard maksimum suhu sesuai SPLN 64:1985 Standar Batas Suhu dan Kenaikan suhu pada komponen dan bahan kontak-kontak tembaga di udara yaitu $95^{\circ} \mathrm{C}$ dan kenaikan suhu $55^{\circ} \mathrm{C}$

Dari hasil inspeksi diatas dapat disimpulkan bahwa penyebab fuse base kendur sehingga menyebabkan timbulnya percikan bunga api, dan kondisi ini jika dibiarkan terus menerus dapat berdampak pada kerusakan $\mathrm{NH}$ fuse (putus) sehingga fungsi dari PHB TR akan terganggu dalam pendistribusian tenaga listrik. Oleh karena itu, evaluasi untuk fuse base yang rusak perlu segera diadakan penggantian fuse base.

\subsubsection{Analisa Gangguan Pemasangan Bendingan (Bypass)}

Bendingan atau bypass adalah gangguan yang terjadi akibat fuse base di beri kawat sehingga tidak menggunakan NH Fuse. Dari Hasil inspeksi 26 April 2016 ditemukan sebanyak 9 bendingan yang terdapat pada gardu KG 333 fasa 1, 2, 3 dengan feeder A,C,dan D (Lampiran C).

Disini membuktikan bahwa gangguan ini tidak menggunakan pengaman lebur sebagai pemutus dan pengaman trafo distribusi dari arus lebih sisi 220 v/380 v. Maka arus yang mengalir tidak terbatas / tidak adanya pembatas arus jadi peralatan akan rusak dan dapat menimbulkan gangguan akibat kuat hantar arus yang di luar nominalnya. Selain itu apabila kawat yang digunakan berukuran besar maka dapat membahayakan. Hal ini terjadi karena pada saat pengerjaan para vendor kekurangan bahan (NH Fuse) sehingga mengambil langkah untuk memberi kawat agar arus tetap mengalir.

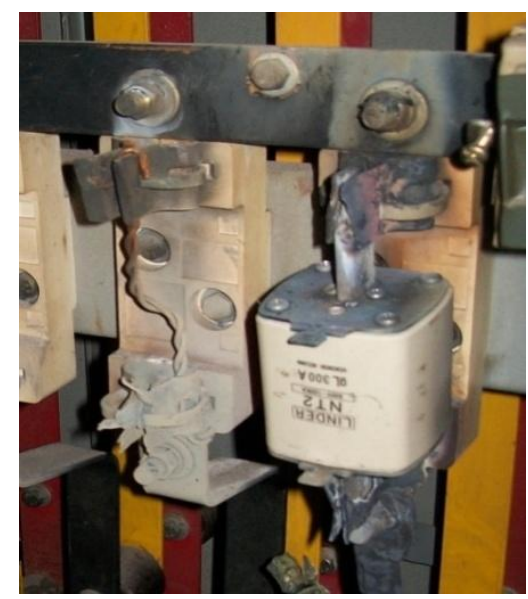

Gambar 3. Bendingan

\subsubsection{Cable Schoen (Sepatu Kabel)}

Apabila arus yang mengalir melalui kabel dengan sambungan yang tidak kencang atau tidak seuai dengan standar perancangan maka sambungan ini akan 
menimbulkan panas yang berlebih dikarenakan ada celah pada sambungan ini. Jika hal ini dibiarkan secara terus menerus akan mengakibatkan kerusakan atau terbakarnya kabel opstig yang nantinya akan berdampak pada kualitas penyaluran listrik ke pelanggan.

Sehingga dengan kondisi ini perlu diperhatikan ketika dilakukan pemasangan sepatu kabel harus dipasang serapat mungkin untuk mengindari adanya celah pada sepatu kabel. Apabila kondisi sepatu kabel sudah rusak akibat panas yang timbul maka perlu dilakukan pergantian sepatu kabel.

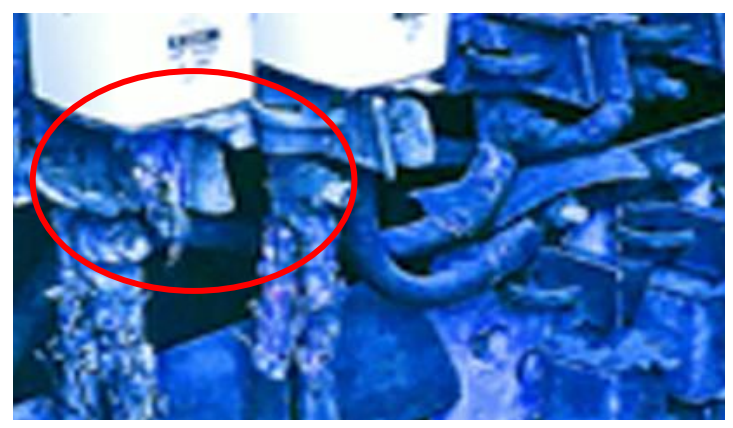

Gambar 4. Sepatu Kabel Rusak

\subsection{Upaya Mengatasi Gangguan Pada PHB TR}

Dari data gangguan yang didapatkan maka kita harus melakukan upaya untuk mengatasi gangguan PHB TR ini agar penyuplaian tenaga listrik ke konsumen tidak mengalami gangguan. Upaya yang dapat dilakukan:

\subsubsection{Upaya Mengatasi NH Fuse Putus}

Gangguan ini dikarenakan beban lebih yang tidak sesuai dengan kapasitas $\mathrm{NH}$ Fuse yang dipakai. Maka sebelum memasang $\mathrm{NH}$ Fuse terlebih dahulu hitung kapasitasnya dengan menggunakan persamaan 1, 2 dan 3 dengan melihat daya trafo yang digunakan.

Menghitung arus NH Fuse

Kapasitas trafo: 400 kVA

Ratio tegangan: $20 \mathrm{kV} / 231-400$ volt Jumlah jurusan di Rak TR : 4 Jurusan

$$
\ln =\frac{400.000 \mathrm{VA}}{\sqrt{3} \times 400 \mathrm{~V}}=577,35 \mathrm{Amp}
$$

Arus Tiap Jurusan $=\frac{577,35 \mathrm{Amp}}{4}$

$$
=144,33 \mathrm{Amp}
$$

KHA NH Fuse dipilih $=144.33$ Amp x 0,9

$$
=129.89 \mathrm{Amp}
$$

Maka dipilih $\mathrm{NH}$ Fuse dengan kapasitas 125 Amp karena nilai ini mendekati nilai KHA NH Fuse yang didapat.

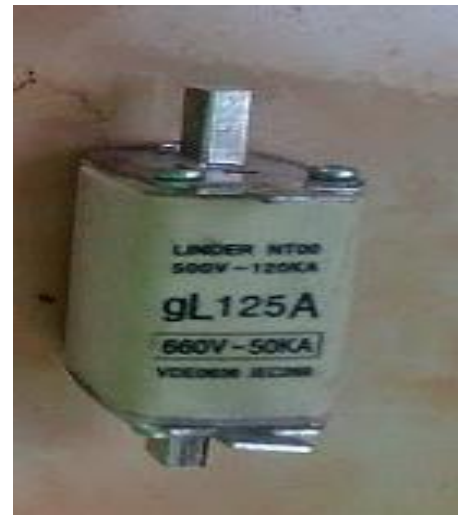

Gambar 5. NH Fuse Kondisi Baik

\subsubsection{Upaya Mengatasi Fuse Base Rusak}

Fuse base yang mengalami kerusakan sebaiknya ditindak lanjut segera agar kualitas penyuluran listrik meningkat. Hal yang harus dilakukan untuk mengatasi gangguan ini yaitu sering melakukan inspeksi ke gardu-gardu distribusi yang ada agar dapat mengetahui perkembangan dari setiap peralatan yang ada pada peralatan listrik di dalam gardu distribusi. Ketika telah melakukan inspeksi dan telah mengetahui gangguan yang terjadi maka harus melakukan penggantian terhadap fuse base yang rusak dengan target penggantian selama 1 bulan.

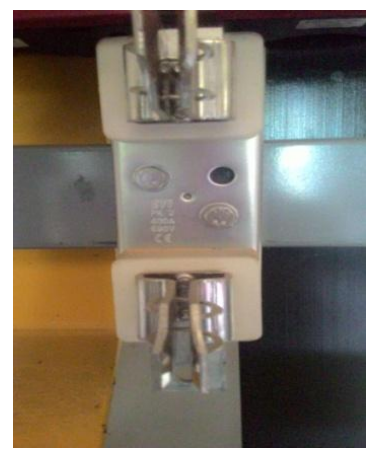

Gambar 6. Fuse Base Kondisi Baik 


\subsubsection{Upaya Mengatasi Bendingan}

Untuk mengatasi bendingan ini sebaiknya sebelum melakukan penggantian $\mathrm{NH}$ Fuse para vendor mengecek terlebih dahulu ketersediaan dari $\mathrm{NH}$ Fuse di kantor. Selain itu para tim inspeksi yang bertugas menghitung dengan baik berapa jumlah $\mathrm{NH}$ Fuse yang mengalami kerusakan serta kapasitas dari NH Fuse yang rusak sehingga gangguan seperti ini tidak lagi terjadi. Untuk pemasangan bendingan yang telah ditemukan segera melakukan penggantian dengan menggunakan $\mathrm{NH}$ Fuse yang sesuai dengan kapasitas PHB TR. Target penggantian dari fuse base yang dibending kawat ke $\mathrm{NH}$ Fuse maksimal 1 bulan.

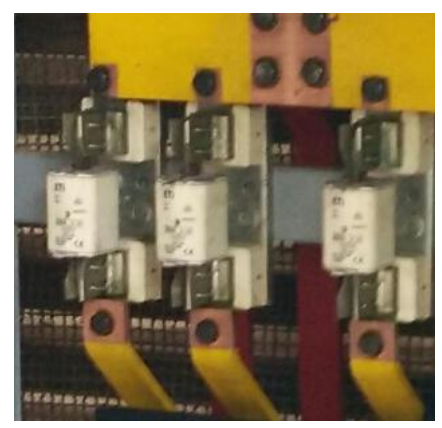

Gambar 7. Bendingan Kawat Diganti NH Fuse

\subsubsection{Kabel Schoen (Sepatu Kabel)}

Untuk mengurangi gangguan yang terjadi akibat kabel schoen yang kurang kencang pada saat pemasangannya maka para pekerja harus memiliki tingkat ketelitian yang baik tentang standar perancangan sehingga mengurangi celah yang dapat mengakibatkan panas yang berlebih. Selain itu pada saat melakukan pemeliharaan sebaiknya para pekerja mengecek keadaan dari setiap baut-baut yang terdapat pada peralatan listrik yang ada di gardu distribusi.

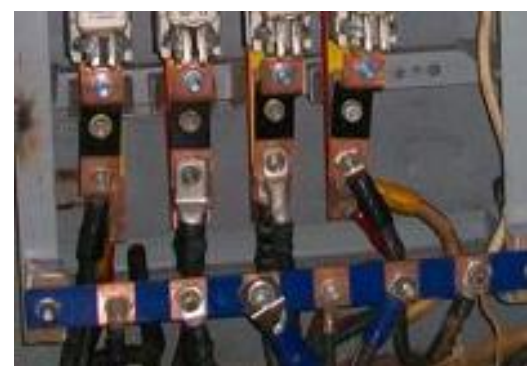

Gambar 8. Sepatu Kabel Kondisi Baik

\section{KESIMPULAN}

1. Kinerja dari suatu Perangkat Hubung Bagi Tegangan Rendah (PHB TR) yaitu sebagai penghubung dan pembagi atau pendistribusian tenaga listrik dari output trafo sisi tegangan rendah TR ke Rel pembagi dan diteruskan ke Jaringan Tegangan Rendah(JTR) melalui kabel jurusan (Opstyg Cable) yang diamankan oleh $\mathrm{NH}$ Fuse jurusan masing-masing.

2. Penyebab gangguan PHB TR adalah:

a. Fuse base rusak dimana gangguan ini terjadi karena fuse yang digunakan tidak sesuai dengan ukuran Fuse Base, selain itu juga dalam pemasangannya tidak sesuai dengan standar pengerjaan

b. NH fuse putus dimana gangguan ini terjadi karena beban lebih dari pemasangan baru, penambahan daya, dan adanya penarangan jalan umum sistem cantol.

c. Bendingan, hal ini terjadi karena fuse base dibending menggunakan kawat sehingga arus tetap mengalir tetapi hal ini membahayakan sebab tidak menggunakan pengaman arus lebih sehingga memungkinkan kerusakan pada trafo

d. Schoen Kabel (Kabel Sepatu) dimana gangguan ini terjadi karena sepatu kabel yang pengepresannya tidak kencang pada kabel opstig sehingga timbul celah dimana celah ini dapat menimbulkan panas

3. Agar penyuplaian tenaga listrik ke pelanggan tidak mengalami gangguan maka sebaiknya dilakukan upaya untuk mengatasi gangguan-gangguan tersebut

4. Inspeksi gardu berfungsi sebagai pencegah terjadinya gangguan dengan mengetahui lebih dini material - material yang berpotensi gangguan untuk di jadikan skala prioritas. 


\section{REFERENSI}

Anonim. 1985. PT PLN (Persero), "SPLN 118-3-1:1996 Perangkat Hubung Bagi".

Anonim. 2010. PT PLN (Persero), "Buku 3 Standar Konstruksi Jaringan Tegangan Rendah Tenaga Listrik".

Anonim. 2010. PT PLN (Persero), "Buku 4 Standar Konstruksi Gardu Distribusi Dan Gardu Hubung Tenaga Listrik".

Darsono Djonjang. 2005. "Diktat PHB TR PHB TM".
Izhar. 2014. "Upaya Penurunan Gangguan $\mathrm{NH}$ Fuse Dengan Mengoptimalkan Analisa Laporan Gangguan Harian Dan Inspeksi Gardu Di Area Tanjung Priok".

Wahyudi SN. 2014. "Teori Tentang Jaringan Distribusi, Gardu Distribusi, Dasar-Dasar Listrik, Pemeliharaan JTM, JTR, GD dan APP". 